\title{
As Tutelas Diferenciadas e o Sistema de Produção Capitalista
}

\author{
Flávio Luís de Oliveira*
}

Sumário: 1. Introdução; 2. As tutelas jurídicas e as demandas sociais; 3 . Algumas reflexões acerca da reforma do processo civil.

\section{Introdução}

Nas nascentes democracias, os procedimentos jurídicoadministrativos foram concebidos em conjunturas políticas pouco democráticas, informadas por estratégias de exclusão das demandas sociais majoritárias.

Acompreensão do processo de inclusão destas demandas no âmbito das políticas públicas, e mesmo do ordenamento jurídico estatal, requer o enfrentamento de uma complexidade estrutural: a colidência entre interesses dos detentores do capital, de um lado, e dos interesses da classe trabalhadora, do outro. ${ }^{1}$

Assim, é evidente a tensão entre a democracia e o modo de produção capitalista, onde as demandas majoritárias sofrem um processo seletivo, compatível com a estrutura (liberal) que impede a materialização de um rol de funções estatais, o que gera a fragilidade do Estado de bem-estar social.

No âmbito da atuação política, a crise de representação ensejou a atuação dos grupos de pressão, cristalizando o dissídio milenar que se trava entre o indivíduo e a coletividade, fator de difícil integração, decorrente de traços humanos imutáveis no plano individual, requerendo políticas hábeis de conciliação na esfera coletiva.

* Professor de Direito Civil da Faculdade de Direito de Marília. Mestrando em Direito na Universidade Federal do Paraná. Advogado em Marília - S.P.

1 Cf. Manoel Eduardo Alves Camargo e Gomes. Apontamentos sobre alguns impactos do projeto neoliberal no processo de formação de tutẹlas jurídico-políticas in Direito e Neoliberalismo. Curitiba, Edibej, 1.996. p. 120.

Revista da Faculdade de Direito da UFPR, Curitiba, a. 29, n. 29, 1996, p. 189-197 
$\mathrm{Na}$ espacialidade jurídica, as codificações se apresentam desvinculadas da realidade social, ocasionando, não raras vezes, incompletudes por deficiência ou por exuberância, o que revela uma "ditadura normativa" assistemática, incompatível com a teoria do ordenamento jurídico. ${ }^{2}$

Portanto, o capitalismo é um sistema em que as relações entre as pessoas e as coisas (propriedade) são diferenciadas das relações das pessoas entre si (contratos). "Os Estados são tão constrangidos pela economia, especificamente pelos proprietários privados dos recursos produtivos, que os governos não podem empreender quaisquer ações contrárias a esses interesses.

Assim sendo, é o "capital quem governa". 3

\section{As Tutelas Jurídicas e as Demandas Sociais}

Marinoni, introduz sua recente obra, com esta preocupação: "Em um determinado momento o processualista acordou e percebeu que a justiça civil era elitista porque afastada da grande maioria da população, que por várias razões evitava recorrer ao Poder Judiciário, e, inefetiva, já que não cumpria aquilo que prometia, principalmente em virtude de sua lentidão". ${ }^{4}$

No ordenamento pátrio, isto ocorreu em virtude da sistemática do código de processo civil concebido através do isolamento em livros, verificando-se uma universalização da ordinariedade, com a conseqüente eliminação das formas de tutelas sumárias satisfativas (antecipatórias), fato que não se traduz uma peculiaridade do nosso direito, mas sim das civilizações contemporâneas.

2 Cf. Norberto Bobbio. Teoria do Ordenamento Jurídico. Brasília, Editora UnB, 1.994. p. 122.

3 Neste sentido, Adam Przeworsky: "Sob o capitalismo, o Direito e a ideologia tratam toda propriedade da mesma maneira, obscurecendo a distinção entre recursos produtivos e artigos de consumo que define as classes sociais. Sob o capitalismo, o Direito e a ideologia tratam as partes do contrato da mesma maneira, como "indivíduos", omitindo o fato de que os trabalhadores, que não podem sobreviver sem vender sua capacidade de trabalho, são obrigados a entrar em contratos de emprego. As instituições políticas tratam a todos como "cidadãos" em abstrato. (Estado e economia no capitalismo, Rio de Janeiro, Relume-Dumará, 1995, p. 107).

4 Luiz Guilherme Marinoni. A antecipação da tutela na reforma do processo civil. São Paulo, Malheiros editores, 1995, p. 13. 
No processo de conhecimento devido a contemplação à ordinariedade, o juiz pode declarar tudo, mas nada faz no campo da executividade, da realidade. É procedimento de cognição plena no plano horizontal e exauriente no plano vertical, que abarca a totalidade do conflito e que tem por fim a decisão definitiva com base no chamado "juízo de certeza", derivado da "busca da verdade".

Nesta tessitura, a verossimilhança era temida, pois abria margem ao subjetivismo do magistrado, assim, este era apenas a bouche de la loi (boca da lei), o que demonstra uma relação entre a aludida "busca da verdade" e a "neutralidade".

Tal concepção foi alimentada pela teoria unitária do ordenamento que supõe a insuficiência das normas de direito material para a composição da lide, a qual somente poderia se dar, através da sentença de cognição plena e exauriente.

Assim, o procedimento ordinário, permite a manutenção do conflito de interesses por longo tempo o que interessa ao réu e aos detentores do poder econômico, e, vedando a interferência do magistrado no conflito de interesses, através de liminar antecipatória da decisão, faz valer a hipótese de não poder julgar por "verossimilhança". 5

Hodiernamente, o mesmo julgador que buscava a verdade, agora se contenta com o julgamento antecipado da lide com base nos efeitos da revelia. Na verdade, o que sempre se buscou foi dar oportunidade para a contestação; além disso, a "certeza", em alguns casos, pode caracterizar aquilo que não é certo, e por conseqüência, ser desfeita via ação rescisória!

Portanto, a ordinariedade deve ser reservada para os casos em que a probabilidade da existência ou inexistência do direito que as partes alegam possuir, seja igual, em que só após a instrução poderia o juiz decidir; mas não servirá para os casos em que a parte demonstra, desde logo, a alta probabilidade da existência do direito pleiteado.

Exigir procedimentos adequados à tutela dos novos direitos é atender ao princípio do acesso à justiça - não basta ter acesso à justiça, exige-se que o acesso seja facilitado e privilegiado por instrumentos adequados à "tutela de cada direito" (O Estado, a partir do período da cognitio extra ordinem $\mathrm{e}$

5 Idem. Efetividade do processo e tutela de urgência. Porto Alegre, Sérgio Antonio Fabris editor, 1994, p. $03-10$.

Revista da Faculdade de Direito da UFPR, Curitiba, a. 29, n. 29, 1996, p. 189-197 
o conseqüente surgimento da jurisdição, têm a obrigação de criar os mecanismos para tal).

Desta feita, quem fala em adequada tutela jurisdicional entende que o princípio da inafastabilidade não apenas veda que se exclua a apreciação, como garante o direito ao processo efetivo, é, por conseguinte, a eficiência do judiciário com a superação dos pontos sensíveis que obstam a prestação jurisdicional. $^{6}$

Se o processo visa a efetividade da tutela jurisdicional, e se essa efetividade deve atender às peculiaridades do direito material, se este estiver sob uma situação de emergência, terá o seu titular direito à tutela antecipada. Mesmo porque, a efetividade só se alcança quando a vantagem atingida pela tutela jurisdicional equivale àquela que seria obtida pela tutela privada.

Por outro lado, o devido processo legal não é realizado pela delonga procedimental que leva ao sacrifício do direito do autor que o demonstra desde o início, com razoável índice de probabilidade.

Sendo assim, a tutela jurisdicional deve realizar a tutela dos direitos dos cidadãos e o princípio da inafastabilidade do controle jurisdicional, constitui, em verdade, a principal garantia destes direitos.

Portanto, aquelas concepções exacerbadas sobre a ação abstrata não mais sobrevive (a não ser em relação a propositura da ação processual, com a indicação da "pretensão" como meio de realização do direito material) porque se prestava apenas à neutralidade do processo como um fim em si mesmo, deturpando a sua instrumentalidade.

Hoje, a interpretação correta do artigo 75 do código civil: "a toda pretensão de direito corresponde uma ação que o assegura", nos conduz a duas reflexões:

6 Nesta linha, Cândido Rangel Dinamarco: "O escopo jurídico da jurisdição não é a "composição" das lides, ou seja, o estabelecimento da regra que disciplina e dá solução a cada uma (refere-se à chamada "composição da lide" - acrescentei) delas em concreto; e regra do caso concreto já existia antes, perfeita e acabada, interessando agora dar-lhe efetividade, ou seja, promover a sua atuação. O escopo da "atuação da vontade concreta da lei" é tão intimamente ligado à tese dualista, que por expressivos defensores desta fórmula assim construída, tem sido apontada também como uma das características fundamentais da própria jurisdição (ao lado do caráter substitutivo). (A instrumentalidade do processo, São Paulo, Malheiros editores, 1993. p. 209). 
1) as peculiaridades do direito material permite o ajuste da tutela jurisdicional à pretensão, assim o artigo em exame perde o caráter de imanentista se considerarmos que a cada afirmação de direito corresponde uma ação (um direito sujeito à situação de dano iminente exige procedimento e provimentos diversos do ordinário).

2) A ausência de debates sobre a relativização entre direito e processo, processo de conhecimento e de execução, consagrou a tẹse da elite que criou procedimentos céleres, extremamente ligados aos seus interesses, v.g. o decreto-lei $\mathrm{n}^{\circ} 911 / 69$, ao passo que, em outras situações, sustentavam a necessidade do "juízo de certeza" permeado pela ordinariedade divorciada de atividades executivas, o que revelou a falência do sistema tradicional, notadamente nas questões de massa, onde a sentença não tinha mais o que proteger, v.g. danos ao meio ambiente.

Nesta linha, Chiovenda já dizia: "O processo deve dar a quem tem um direito, tudo aquilo e exatamente aquilo que ele teria direito de obter".

Oprincípio da nulla executio sine titulo (nula execução sem título) é que afasta o juízo de verossimilhança e mantém o mito da neutralidade, assegurando a separação do processo de conhecimento do processo de execução. Isto porque, ao exigir o título, está a exigir "verdade" o que se relaciona com a cognição exauriente, com trânsito em julgado. ${ }^{7}$

Destarte, não se pode falar em direito à tutela jurisdicional apenas como direito à sentença, alheia à natureza do direito substancial, e, neste aspecto, diferenciamos eficácia e eficiência (esta compromissada com o custo-benefício do processo, em consonância com os princípios informativos do processo civil).

Oprocedimento ordinário pela sua morosidade não é adequado à tutela de todas as situações de direito material. Por ser inaceitável, a tutela cautelar transformou-se em técnica de sumarização, devido ao mito: "cognição sumária não dá margem à execução por gerar sentença não definitiva".

No plano fático, isto se verificou com espeque no artigo 798 do CPC.

7 Cf. Luiz Guilherme Marinoni. A antecipação da tutela na reforma do processo civil. São Paulo. Malheiros editores, 1995 , pp. 47/54.

Revista da Faculdade de Direito da UFPR, Curitiba, a. 29, n. 29, 1996, p. 189-197 
Atutéla antecipatória genérica (art. $273 \mathrm{CPC}$ ) e a tutela específica das obrigações de fazer e não fazer (art. $461 \mathrm{CPC}$ ), esta já constante no código de defesa do consumidor (lei 8.078/90 - art. 84) introduzidas pela reforma do processo civil, quando do seu início, certamente contribuirão para eliminar os "encargos" do tempo do processo.

Como foi dito, a efetividade da tutela jurisdicional passa, necessariamente, pela via de adaptação às peculiaridades do direito material, o que se dá com a busca de tutelas diferenciadas, logo, de procedimentos diversos.

Assim, a técnica antecipatória é, antes de mais nada, uma técnica de distribuição do ônus da morosidade do processo, pois já dizia o mestre Rui Barbosa: "Justiça atrasada não é justiça, senão injustiça qualificada e manifesta". 8

\section{Algumas Reflexões Acerca da Reforma do Processo Civil}

Atualmente, creio que esta ideologia, comprometida com o sistema de "privilégios", permanece materializada, dentre outros, em dois aspectos constantes das mini-reformas do processo civil brasileiro:

1) Urge refletirmos sobre a técnica dos títulos executivos extrajudiciais, como técnica de sumarização, sendo vedado ao juiz averiguar a existência do direito que o título faz presumir presente.

Como o título indica apenas alto grau de probabilidade, abre-se mão da certeza, criando o risco de eventual erro quanto à existência do direito provável. ${ }^{9}$

8 Rui Barbosa apud Reis Friede. Liminares em tutela cautelar e tutela antecipatória. Rio de Janeiro, Editora destaque, 1996, p. 87.

9 Neste sentido, imensurável magistério de Luiz G. Marinoni, citando Proto Pisani: "Os títulos executivos extrajudiciais sempre privilegiaram determinados sujeitos e seus respectivos direitos, razão pela qual, em atenção ao princípio da isonomia, o professor de Florença propõe o alargamento da técnica dos títulos extrajudiciais a todas as hipóteses em que um documento idôneo seja capaz de fornecer um grau de probabilidade considerado suficiente, independentemente do peso político dos sujeitos que poderão usufruir dos títulos. A técnica dos títulos executivos extrajudiciais, como é óbvio, não pode privilegiar posições sociais, devendo estar atenta apenas a uma maior efetividade do processo". 
Assim, a ampliação do rol dos títulos executivos extrajudiciais, efetivada pela Lei 8.953 de 13.12.94, no que concerne às debêntures, evidencia a manutenção de alguns vícios, mantidos através da atuação típica. do "governo do capital" que via atuação normativa ou ideológica, encobre as diferenças reais entre a elite, detentora do poder econômico e os consumidores da prestação jurisdicional, estes, relegados ao procedimento ordinário. $^{10}$

Portanto, indaga-se:

Este "novo" título executivo extrajudicial é freqüentemente utilizado pela maioria dos consumidores da justiça?

É um instrumento "comum" às diversas classes sociais ou inerente aos detentores do meio de produção capitalista?

Oaumento do número dos referidos títulos concretiza as aspirações de uma minoria que, neste caso, não questiona a finalidade desta técnica. Assim, já alertava Segni: "nunca houve um repúdio a longa e laboriosa teoria dos títulos de crédito, por meio dos quais os "empresários" podiam livrar-se do tão elogiado procedimento ordinário, servindo-se do mais puro e bem feito processo sumário que a doutrina moderna jamais concebeu". ${ }^{11}$

2) No que pertine aos "processos monitórios", esta técnica de sumarização consiste em antecipar a eficácia condenatória por meio de uma decisão, destinada a desaparecer se o réu comparece e contesta a ação.

Diante da estrutura do atual código de processo civil, não há que se cogitar "em um enorme progresso" em relação ao tema, pois a exigência quanto a necessidade de constar no mandado de citação, a cominação de que se o demandado não contestar a ação, ter-se-ão verdadeiros os fatos afirmados pelo autor (art. 285), caso em que o juiz poderá, desde logo, proferir sentença de mérito (art. 330, II), em virtude de se operar os efeitos da revelia (art. 319), evidencia, há mais de duas décadas, um caminho aberto

10 Assim, Miliband observa: “As sociedades capitalistas são caracterizadas pela desigualdade. Em todas as sociedades capitalistas um pequeno grupo controla uma enorme parcela da riqueza e deriva vários privilégios dessa propriedade. Estas mesmas pessoas fazem parte do aparelho de Estado como funcionários nomeados, juízes ou políticos eleitos. Logo, as sociedades capitalistas são governadas por uma "classe dirigente": as elites econômicas formam uma "classe dominante" e a classe dominante é a mesma que a "elite estatal". Assim, Lênin, retornando à Marx, qualificou a democracia capitalista com uma "ditadura da burguesia": a igualdade formal não é capaz de superar a "desigualdade real". (apud Adam Przeworsky, op. cit., p. 116).

11 Cf. Ovídio Baptista da Silva. Curso de processo civil. Porto Alegre, Fabris, 1987, v.1, p. 105.

Revista da Faculdade de Direito da UFPR, Curitiba, a. 29, n. 29, 1996, p. 189-197 
ao postulante, e, simultaneamente, o fundamento do julgamento antecipado da lide, dentro do processo de conhecimento.

Portanto, há necessidade de analisarmos as mutações do ordenamento jurídico, através do método interdisciplinar, tarefa que não se revela fácil, mas traduz o caminho a ser palmilhado pelo jurista preocupado com o confinamento teórico e científico do Direito.

Alguns doutrinadores ${ }^{12}$ insistem em desprezar esta atividade, defendendo o isolamento do objeto de análise, mas claudicam ao tentar compreender as ideologias estruturais do sistema, que permeiam a nossa realidade.

Finalmente, a discussão sobre o Estado e a economia, e por conseqüência, em relação ao Direito, não é apenas acadêmica, constituindo-se a questão central dos debates políticos contemporâneos.

Oconflito entre o público e o privado manifesta-se claramente no mundo jurídico, que é informado por esta tensão, exacerbada por sua vez, pelo regime democrático, e, indubitavelmente, inseparável do sistema de produção capitalista.

\section{BIBLIOGRAFIA}

BOBBIO, Norberto. Teoria do ordenamento jurídico. Brasília: Editora UnB, 1994.

DINAMARCO, Cândido Rangel. A instrumentalidade do processo. São Paulo: Malheiros editores, 1993.

12 J.J. Calmon de Passos: “Tenho uma dificuldade imensa para compreender cognição sumária, cognição superficial, cognição disso e daquilo. Para mim, toda cognição é aquela adequada para o tipo de decisão a ser dada. Só poderei decidir quanto tiver convencimento de que os fatos ocorreram de determinada maneira. Não entendo, por exemplo, como, com fundamento no que o autor alega, deferir isso ou aquilo. Para mim, o que se alega ao magistrado e nada é a mesma coisa. O que se prova ao magistrado é tudo. Seja qual for a tutela - provisória, definitiva ou liminar -, na conclusão última do processo, com antecipação ou sem, é decisão transparente, que pode dizer por que a está dando e quais os fundamentos que encontrou para dá-la. Não entendo por que em um processo há antecipação, enquanto em outro há perpetuação. O direito não existe antes de o magistrado dizer que aquilo é direito. Antes disso, o que há são conflitos de interesses, pretensões, postulações, e o magistrado só pode dizer que uma determinada situação configura um direito quando ele está maduro em seu convencimento, e essa maturidade é aquela exigida para o tipo de decisão que ele vai dar: provisória, definitiva, antecipatória, etc.". (A questão das liminares e o perecimento do direito in série de cadernos do C.E.J., n'10, p. 14) 
FRIEDE, Roy Reis. Liminares em tutela cautelar e tutela antecipatória. Rio de Janeiro: Editora destaque, 1996.

GOMES, Manoel Eduardo Alves Camargo e, et. al. Direito e neoliberalismo. Curitiba: Edibej, 1996.

MARINONI, Luiz Guilherme. Efetividade do processo e tutela de urgência. Porto Alegre: Sérgio Antônio Fabris editor, 1994.

A antecipação da tutela na reforma do processo civil. São Paulo: Malheiros editores, 1995.

PASSOS, J. J. Calmon de. A questão das liminares e o perecimento do direito in Série cadernos do C.E.J., $\mathrm{n}^{\circ} 10$, p. 11-16.

PRZEWORSKY, Adam. Estado e economia no capitalismo. Rio de Janeiro: Relume-dumará, 1995. 